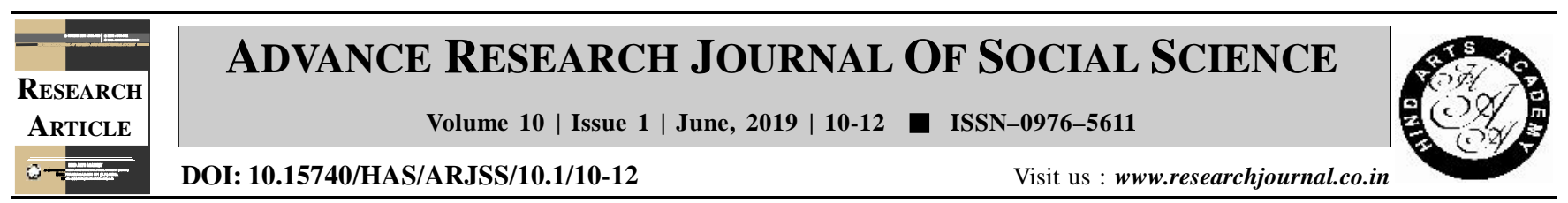

\title{
Occupational stress of the assistant employees of Assam Agricultural University of Jorhat
}

Arifa Momtaz Begum, Zionvarzing Thiek* and Tulika Borah Department of Human Development and Family Studies, College of Community Science, Assam Agricultural University, Jorhat (Assam) India

(Email : thiekzionvarzing@gmail.com)

\section{ARTICLE INFO :}

Received

Revised

09.02.2019

Accepted

: 03.05 .2019

: 14.05 .2019

KEY WORDS :

Stress, Occupational stress

HOW TO CITE THIS ARTICLE :

Begum, Arifa Momtaz, Thiek, Zionvarzing and Borah, Tulika (2019).

Occupational stress of the assistant employees of Assam Agricultural University of Jorhat. Adv. Res. J. Soc. Sci., 10 (1) : 10-12, DOI: 10.15740/HAS/ ARJSS/10.1/10-12. Copyright@2019 : Hind Agri -Horticultural Society

*Author for correspondence

\begin{abstract}
Occupational stress is the interaction of the worker and the conditions of work. The study was conducted to identify the level of occupational stress of the Assistant Professors and equivalent rank at Assam Agricultural University. A total number of 50 respondents including Assistant professors, Subject Matter Specialist and Junior Scientists were selected randomly for the present study. A well developed and widely used tool known as occupational stress index (OSI) in the Indian context (Srivastava and Singh, 1984) was used to assess the occupational stress of the sample. The questionnaire consists of 46 statements. The items relate to almost all relevant components of the job life which cause stress in some way or the other. Total score on this scale is considered for the assessment of occupational stress. More the score on this scale indicates more stress. The findings of the present study revealed that $(68 \%)$ of the respondents were highly stressed due to overload of work and 54 per cent of the respondents were moderately stressed due to the reason of under participation. Due to unreasonable group and political pressure 46 per cent of the respondents showed low level of stress.
\end{abstract}

